\title{
Rapid, simple, and sensitive detection of the ompB gene of spotted fever group rickettsiae by loop-mediated isothermal amplification
}

\author{
Lei Pan ${ }^{1}$, Lijuan Zhang ${ }^{1 *}$, Guiqiang Wang ${ }^{2}$ and Qinghui Liu ${ }^{3}$
}

\begin{abstract}
Background: Spotted fever caused spotted fever group rickettsiae (SFGR) is prevalent throughout China. In this study, we describe a rapid, simple, and sensitive loop-mediated isothermal amplification (LAMP) assay targeting the ompB gene of spotted fever group rickettsiae ideal for application in China. The LAMP assay has the potential to detect spotted fever group rickettsiae early in infection and could therefore serve as an alternative to existing methods.
\end{abstract}

Methods: A set of universal primers which are specific 7 common species of spotted fever group rickettsiae in China were designed using PrimerExplorer V4 software based on conserved sequences of ompB gene. The sensitivity, specificity and reproducibility of the LAMP were evaluated. The LAMP assay for detecting SFGR was compared with conventional PCR assays for sensitivity and specificity in early phase blood samples obtained from 11 infected human subjects.

Results: The sensitivity of the LAMP assay was five copies per reaction ( $25 \mu \mathrm{L}$ total volume), and the assay did not detect false-positive amplification across 42 strains of 27 members of the order Rickettsiales and 17 common clinical pathogens. The LAMP assay was negative to typhus group rickettsiae including $R$. prowazekii and $R$. typhi for no available conserved sequences of $\mathrm{OmpB}$ was obtained for designing primers.

To evaluate the clinical applicability of the LAMP assay, a total of 11 clinical samples, 10 samples confirmed serologically (3 cases), ecologically (1 case), by real-time polymerase chain reaction (PCR; 2 cases), ecologically and by real-time PCR (1 case), and serologically and by real-time PCR (3 cases) were analyzed by the ompB LAMP assay. Data were validated using a previously established nested PCR protocol and real-time PCR. A positive LAMP result was obtained for 8 of the 10 confirmed cases (sensitivity, 73\%; specificity, 100\%), while none of these samples were positive by nested PCR (sensitivity, 0\%; specificity, 100\%).

Conclusions: The LAMP assay described here is the most reliable among the three methods tested and would be an ideal choice for development as a rapid and cost-effective means of detecting SFGR in China.

Keywords: Rickettsia, LAMP assay, Molecular detection, Spotted fever, Clinical microbiology

\footnotetext{
* Correspondence: zhanglijuan@icdc.cn

'Department of Rickettsiology, National Institute for Communicable Disease Control and Prevention, China CDC, Changping P.O.BOX5, Beijing 102206,

People's Republic of China

Full list of author information is available at the end of the article
} 


\section{Background}

Spotted fever is caused by obligate (Gram-negative) intracellular spotted fever group rickettsiae (SFGR) [1]. SFGR are widely distributed throughout the world, causing both emerging and re-emerging infectious diseases $[2,3]$. People working in wild fields, including farm workers, forest workers, field soldiers, and travelers, are the main populations susceptible to SFGR infection. In 1984, only five species of SFGR were confirmed as human pathogens but that number has since risen to more than ten, such us Rickettsia massiliae, $R$. raoultii, $R$. parkeri, $R$. africae, $R$. felis, $R$. japonica, $R$. peacokii, $R$. helvetica, $R$. montanensis, $R$. monacensis, $R$. rhipicephali. There are three main pathogenic SFGR in China: $R$. sibirica [4], $R$. heilongjiangensis [5], and R. sibirica mongolotimonae [6].

Unrecognized pathogens, combined with the lack of a rapid and sensitive diagnostic method for identifying SFGR, may be responsible for causing delayed treatment or misdiagnosis that could lead to the development of severe disease and fatality [7]. The greatest challenge to clinicians is not therapy but the difficult diagnosis during the early phase of infection. Conventional serodiagnosis requires serum from both the acute and convalescent stages of infection, the latter of which would be unavailable at early diagnosis. Although SFGR can be isolated and reliably identified from samples cultivated in the laboratory, this approach for early diagnoses also has its drawbacks, as this method is generally associated with low isolation rates and requires sophisticated and expensive equipment. Other methods that have been applied for this purpose, such as those involving the polymerase chain reaction (PCR) (i.e., conventional, nested, and realtime PCR), also require expensive, specialized instruments those are not widely available.

Loop-mediated isothermal amplification (LAMP) is a novel nucleic acid amplification method that was developed in 2000 [8]. LAMP is a highly sensitive, specific and simple technique that under isothermal conditions (60$65^{\circ} \mathrm{C}$ ) can generate up to a $10^{9}$-fold amplification in less than an hour, making LAMP a rapid and simple diagnostic tool for identifying SFGR. In this study, we aimed to develop a rapid, sensitive and specific assay targeting the ompB gene to detect SFGR infection in humans from rural areas of China.

\section{Methods}

\section{Clinical samples}

Between 2007 and 2009, we obtained 11 samples from clinical SFGR cases from four different hospitals (Peking University First Hospital, Laizhou People's Hospital, Beijing Friendship Hospital, and 302 Military Hospital of China). This study was approved by the Human Research Ethics Committee of the Chinese Center for Disease Control and Prevention (China CDC). Before entry into the study, each patient was informed about the purpose and procedures of the research and written consent was obtained. Two milliliters of ethylenediaminetetraacetic acid (EDTA)-anticoagulated blood and $2 \mathrm{~mL}$ of nonanticoagulated blood were collected during the acute phase of illness for culture and for the detection of IgM and IgG antibodies, respectively. DNA was extracted from the remaining clots for nested PCR [9], real-time PCR [10], and the LAMP assay. A second serum sample was collected during the convalescent stage (2-4 weeks after acute phase) to detect IgG antibodies. Each case was confirmed by indirect fluorescent antibody analysis (IFA; four-fold increase or decrease in IgG antibody titer), as recommended by the World Health Organization (WHO), and the analysis of clinical criteria was able to exclude other febrile illnesses [7,10-12]. All the patients were eventually cured by administration of specific antibiotic therapy for rickettsiosis.

\section{Laboratory strains}

The specificity of the LAMP assay was determined using a total of 42 strains of the order Rickettsiales (Table 1). These strains were provided by Dr Raoult D from the WHO Collaborating Centre for Rickettsial Reference and Research (Marseille, France). Other common clinical pathogenic bacteria were obtained from the relevant department of the China CDC (Table 1). Genomic DNA was extracted from cultured cells using the QIAamp DNA Mini Kit (Qiagen, Hilden, Germany). In addition, total blood DNA from healthy humans, cattle, horses, goats, and mice was isolated for use as negative controls. Before being used to determine the specificity of the LAMP assay, each bacterial DNA sample was first prescreened by PCR using universal prokaryotic bacterial $16 \mathrm{~S}$ rRNA primers, as previously described [13]. Genomic DNA from the 42 strains was tested by LAMP to determine the specificity of the $о т р B$ LAMP assay. All detection assays were performed in triplicate.

\section{LAMP primer design}

A set of universal primers complementary to the $о т р B$ of Rickettsia sp. BJ-90 (GenBank Accession: AY331393) was designed using PrimerExplorer V4 software (http:// primerexplorer.jp; Eiken Chemical Co., Ltd., Tokyo, Japan) based on conserved sequences determined by the nucleotide alignment of $17 \mathrm{ompB}$ GenBank entries (Table 1). These primers were assumed to be specific for SFGR since no available conserved sequences of the oтp $B$ gene were found in the typhus group of rickettsiae, such as $R$. prowazekii and $R$. typhi. The primers were synthesized by Sangon Biotech (Shanghai, China). The primer sequences and their positions relative to the $о т p B$ gene are shown in Table 2 and Figure 1. 
Table 1 Laboratory strains used for determining the specificity of the LAMP assay and aligned sequences for designing primers

\begin{tabular}{|c|c|c|}
\hline Members of the order Rickettsiales & The related species & Aligned sequences \\
\hline Rickettsia prowazekii & Bartonella henselae & Astrakhan rickettsia (AF123708.1) \\
\hline Rickettsia typhi & Bartonella quintana & Israeli tick typhus rickettsia (AF123712.1) \\
\hline Orientia tsutsugamushi (types Karp, Kato and Gilliam) & & Rickettsia mongolotimonae (AF123715.1) \\
\hline $\begin{array}{l}\text { Anaplasma phagocytophilium strains Webster, MRK, } \\
\text { Slovienie and MD }\end{array}$ & $\begin{array}{l}\text { Other common clinical pathogenic } \\
\text { bacteria }\end{array}$ & Rickettsia parkeri (AF123717.1) \\
\hline Rickettsia sibirica & Coxiella burnetii & Rickettsia sp. S (AF123720.1) \\
\hline Rickettsia conorii & Borrelia burgdorferi (2) ${ }^{a}$ & Rickettsia conorii strain Seven (AF123721.1) \\
\hline Rickettsia honei strain marmionii & Escherichia coli $(3)^{a}$ & Rickettsia sibirica (AF123722.1) \\
\hline Rickettsia akari & Vibrio cholerae & $\begin{array}{l}\text { Rickettsia conorii strain Indian tick typhus rickettsia } \\
\text { (AF123726.1) }\end{array}$ \\
\hline Rickettsia rickettsii & Bacillus anthracis & Rickettsia heilongjiangensis (AY260451.1) \\
\hline Rickettsia africa & Haemophilus influenzae (2) ${ }^{a}$ & $\begin{array}{l}\text { Rickettsia heilongjiangensis variant extremiorientalis } \\
\text { (AY280712.1) }\end{array}$ \\
\hline Rickettsia parkeri & Listeria spp. & Rickettsia sp. BJ-90 outer (AY331393.1) \\
\hline Rickettsia japonica & Legionella spp. & $\begin{array}{l}\text { Rickettsia mongolotimonae isolate URRMTMFEe65 } \\
\text { (DQ097083.1) }\end{array}$ \\
\hline Rickettsia slovaca & Yersinia pestis & Rickettsia rickettsii strain Dv090589 (GU395293.1) \\
\hline Rickettsia aeschlimannii & Shigella dysenteriae $(3)^{a}$ & Rickettsia sibirica strain RH05 (HM050273.1) \\
\hline Rickettsia montanensis & Neisseria meningitides & Rickettsia rickettsii (X16353.1) \\
\hline Rickettsia helvetica & Leptospira spp. & Rickettsia japonica (AB003681.1) \\
\hline Rickettsia felis & & Rickettsia africae (AF123706.1). \\
\hline \multicolumn{3}{|l|}{ Rickettsia australis } \\
\hline \multicolumn{3}{|l|}{ Rickettsia canadensis } \\
\hline \multicolumn{3}{|l|}{ Rickettsia bellii } \\
\hline \multicolumn{3}{|l|}{ Rickettsia heilongjiangensis } \\
\hline Ehrlichia chaffeensis & & \\
\hline
\end{tabular}

Note: ${ }^{a}$ : The number in brackets indicates the number of the isolates used in the study.

\section{Reference plasmid}

To determine the sensitivity of the LAMP assay, a recombinant plasmid containing the target sequence of the Rickettsia sp. BJ-90 (GenBank Accession: AY331393) отрB gene was constructed. The sequence located between the F3 and B3 primer binding sites was amplified using primers OP1 (5'-CACCGCCAGCGTTCCCTAT-3') and OP2 (5'-AACTGCTGAAATGGCTGGAC- $\left.{ }^{\prime}\right)$. The resulting $\mathrm{PCR}$ products $(624 \mathrm{bp})$ were cloned into the pEASY-T1 vector using the pEASY-T1 Cloning Kit
(TransGen, China). The recombinant plasmid was quantified by NanoPhotometer (Implen, Germany) and serially diluted (to concentrations of $5^{5}, 5^{4}, 5^{3}, 5^{2}, 5^{1}$, and $5^{0}$ copies $/ \mu \mathrm{L}$ ) to evaluate the limit of detection and reproducibility of the $о m p B$ LAMP assay.

\section{LAMP reaction}

All LAMP reactions were performed using the Loopamp Kit (Eiken Chemical Co., Ltd., Tokyo, Japan) in a $25 \mu \mathrm{L}$ reaction volume containing $1.6 \mu \mathrm{M}$ of each of the FIP

Table 2 Nucleotide primer sets used for the ompB LAMP assay

\begin{tabular}{lcl}
\hline Primer type & Positions & ${\text { Sequence } \mathbf{5}^{\prime} \mathbf{- 3}^{\prime}}^{\mathbf{s}^{\prime}}$ \\
\hline FIP(F1C-F2) & $1287-1308 / 1230-1247$ & GTCACCGCAACATTGCATCTG-GTAACACTGCAGGTGTGAT \\
BIP(B1C-B2) & $318-1339 / 1373-1390$ & TACAGCAATTGAAGCATCAGGT-TCCTAAACGTAACTCGGC \\
F3 & $1210-1227$ & AGGTGATGCTAIIAATCC \\
B3 & $1410-1427$ & CTGTACCITCAGCAAGT \\
LF & $1263-1285$ & ACTAGCACTTGCTAAAGTACCGT \\
LB & $1346-1370$ & GTTGTCCAATTATCAGGAACACATG \\
\hline
\end{tabular}




$$
\begin{aligned}
& 1159 \text { TGCAGCACAG ATTACAGTTC CTAATACTAT GACCCTTAAA GGTAATTTTA CAGGTGATGC TAGCAATCCC GGTAACACTG } 1238
\end{aligned}
$$

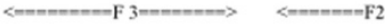

$$
\begin{aligned}
& 1239 \text { CAGGTGTGAT AACTTTTGAT GCTAACGGTA CTTTAGCAAG TGCTAGTGCA GATGCAAATG TTGCGGTGAC AAATAATATT } 1318 \\
& \text { - - < }>-1 \\
& 1319 \text { ACAGCAATTG AAGCATCAGG TGCCGGAGTT GTCCAATTAT CAGGAACACA TGCTGCCGAG TTACGTTTAG GAAATGCCGG } 1398
\end{aligned}
$$

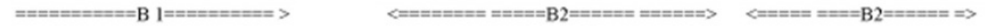

$$
\begin{aligned}
& 1399 \text { TTCTGTCTTT AAACTTGCTG ACGGTACAGT TATAAACGGT AAAGTTAACC AAACTGCTCT TGTCGCCGGT GCTCTTGCAG } 1478 \\
& <== \pm====\mathrm{B} 3 \mathrm{c}== \pm== \pm=>>
\end{aligned}
$$

Figure 1 The rickettsial $o m p B$ gene indicating names and binding sites of primers for LAMP.

and BIP primers, $0.8 \mu \mathrm{M}$ of the LF and LB primers, $0.2 \mu \mathrm{M}$ of the $\mathrm{F} 3$ and $\mathrm{B} 3$ primers, $20 \mathrm{mM}$ Tris- $\mathrm{HCl}$ (pH 8.8), $10 \mathrm{mM} \mathrm{KCl}, 8 \mathrm{mM} \mathrm{MgSO}_{4}, 10 \mathrm{mM}(\mathrm{NH} 4)_{2} \mathrm{SO}_{4}$, $0.1 \%$ Tween-20, $0.8 \mathrm{M}$ betaine, $1.4 \mathrm{mM}$ of each deoxynucleoside triphosphate (dNTP), and $1 \mu \mathrm{L}$ Bst DNA polymerase $(8 \mathrm{U} / \mu \mathrm{L})$. The reaction was incubated in a real-time turbidimeter (model LA200, Teramecs, Tokyo, Japan) at $63^{\circ} \mathrm{C}$ for $60 \mathrm{~min}$ and then at $80^{\circ} \mathrm{C}$ for $5 \mathrm{~min}$ to terminate the reaction. Positive and negative samples were distinguished by a turbidity cutoff value of 0.1 . After amplification, the LAMP products were examined by electrophoresis on $2 \%$ agarose gels stained with ethidium bromide or by visual inspection after the addition of $1 \mu \mathrm{L}$ of $1000 \times$ concentrated SYBR Green I.

\section{Evaluation of the sensitivity, specificity, and reproducibility of the LAMP assay}

To compare the sensitivities of the ompB LAMP assay and general PCR, the serially-diluted reference plasmid (at concentrations of $5^{5}, 5^{4}, 5^{3}, 5^{2}, 5^{1}$, and $5^{0}$ copies $/ \mu \mathrm{L}$ ) containing the target DNA was used to first define the limit of detection. A general PCR using primers OP1 and OP2 was performed as a $25 \mu \mathrm{L}$ reaction containing $0.2 \mu \mathrm{M}$ of each primer, $0.4 \mathrm{mM}$ of each dNTP, and $1 \mathrm{U}$ of Taq DNA polymerase. PCR was performed 35 times using a denaturation step of $94^{\circ} \mathrm{C}$ for $50 \mathrm{~s}$ followed by annealing at $52.5^{\circ} \mathrm{C}$ for $30 \mathrm{~s}$ and extension at $72^{\circ} \mathrm{C}$ for $45 \mathrm{~s}$. The PCR products were electrophoresed on a $1 \%$ TBE agarose gel and stained with ethidium bromide $(1 \mu \mathrm{g} / \mathrm{mL})$.

To evaluate the reproducibility of the LAMP assay, the serially-diluted reference plasmids were amplified in two ways: five different times on the same day or once on each of five consecutive days. The intra-assay coefficient of variation $(\mathrm{CVi})$ and inter-assay coefficient of variation $(\mathrm{CVo})$ were analyzed at the time of peak precipitation, as determined using a real-time turbidimeter, as previously described $[14,15]$. Statistical analysis was conducted using SAS software (version 9.1; SAS Institute, Cary, NC).

\section{Results}

\section{Specificity of LAMP}

To determine the specificity of the LAMP assay for the detection of SFGR, 27 members of the order Rickettsiales were tested for amplification that included seven species of the spotted fever group ( $R$. sibirica, $R$. conorii, $R$. rickettsii, $R$. africa, $R$. parkeri, $R$. japonicai, and $R$. heilongjiangensis). All seven SFGR tested by this method were positive and other common pathogens were not detected by LAMP. These results indicate that the $о m p B$ LAMP assay was specific for SFGR. The LAMP assay developed here did not detect $R$. prowazekii and $R$. typhi even though both possess an oтpB gene but no conserved sequences where primers were design are present in these bacteria.

\section{Sensitivity of LAMP}

The limits of detection of LAMP and PCR for the $о m p B$ gene were 5 and 625 copies per reaction, respectively (Figures 2 and 3). Thus, the LAMP assay is 125 -fold sensitive than conventional PCR for detecting SFGR.

\section{Reproducibility of LAMP}

The minimal detection levels, $\mathrm{CVi}$ and $\mathrm{CVo}$, of the LAMP assay were 1.58 and $3.11 \%$, respectively (Table 3 ).

\section{Examination of clinical samples}

Of the 11 samples that were assayed, seven cases of SFGR infection were confirmed in our laboratory. While

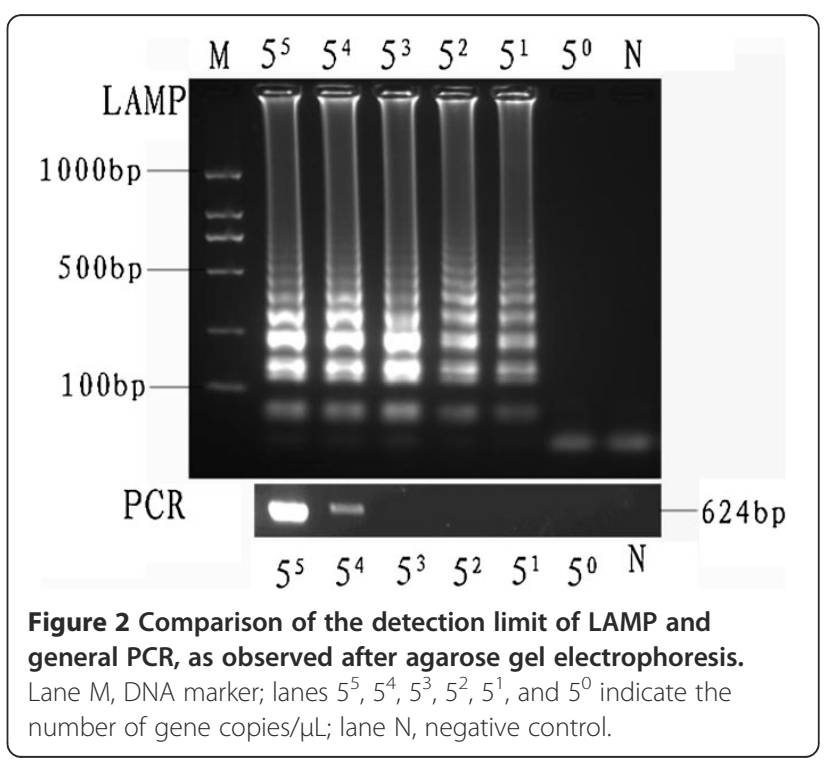




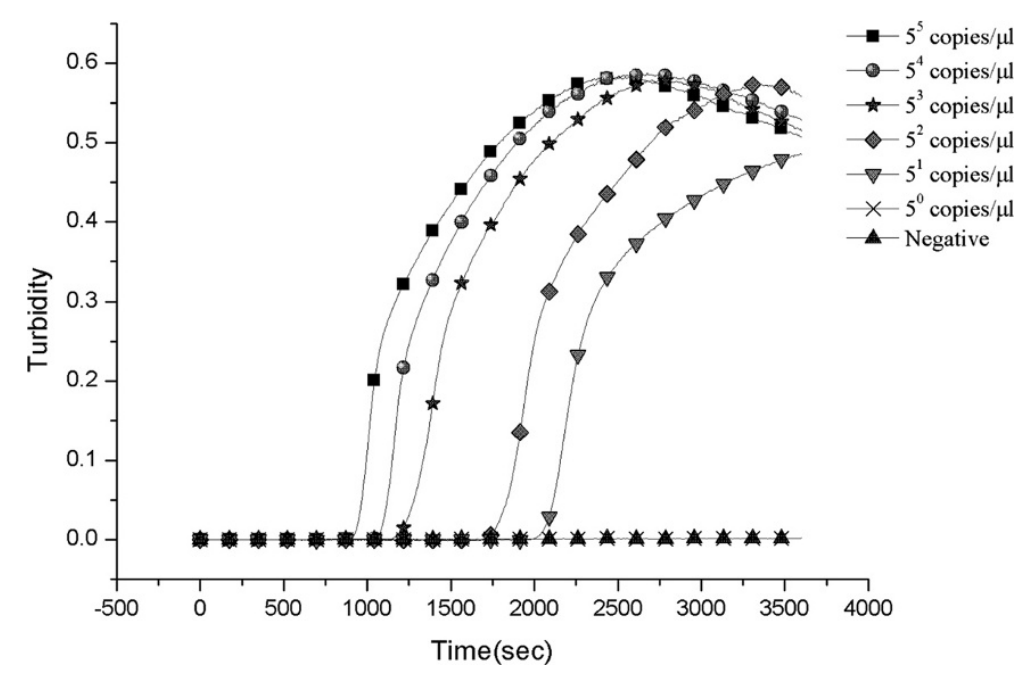

Figure 3 Sensitivity of the LAMP assay as monitored by the real-time measurement of turbidity.

one of the SFGR assignments was made by analysis of bacterial cultures individually, the remaining three were confirmed individually by IFA of acute- and convalescent-phase serum samples, two were confirmed individually by real-time PCR, one was confirmed by both analysis of bacterial cultures and real-time PCR, and three were confirmed by both IFA of acute- and convalescent- phase serum samples and real-time PCR. To evaluate the utility of LAMP for use with clinical samples, the 11 samples analyzed by IFA were also subjected to analysis by LAMP and nested PCR (Table 4). Eight of the 10 confirmed cases of SFGR were positive by the LAMP assay. In contrast, nested PCR did not yield any positive identification.

\section{Discussion}

Although SFGR have been monitored in China for nearly 30 years, infection with SFGR remains widely undiagnosed, a problem that could be the cause of delays in treatment or misdiagnoses that could lead to severe disease and fatal outcomes [3]. The WHO Collaborating Centre for Rickettsial Reference and Research (Marseille, France) regards the IFA as the "gold standard" for the serological testing of rickettsial diseases. The drawback

Table 3 Summary of the CVi and CVo of the time of peak precipitation of serially-diluted plasmids

\begin{tabular}{lcc}
\hline Concentration copies/ $\boldsymbol{\mu L}$ & $\mathbf{C V i}^{\mathbf{a}}$ & $\mathbf{C V o} \%^{\mathbf{b}}$ \\
\hline $5^{5}$ & $1.20 \%$ & $2.22 \%$ \\
$5^{4}$ & $1.40 \%$ & $2.53 \%$ \\
$5^{3}$ & $1.55 \%$ & $2.81 \%$ \\
$5^{2}$ & $1.58 \%$ & $3.11 \%$ \\
\hline
\end{tabular}

${ }^{a}$ Intra-assay coefficient of variation.

${ }^{\mathrm{b}}$ Inter-assay coefficient of variation. of this method, however, is that it requires instrumentation that is not common in rural areas. In China, the availability of the non-specific Weill-Felix's reaction is limited to high-technology settings. However, this method is no longer used as a routine screening method for rickettsial diseases in developing countries. The other drawback to serological assays is that it requires convalescent-phase serum, a requirement that effectively rules out its use for early diagnosis. Molecular diagnostic techniques based on PCR have gradually replaced tedious culture isolation methods for disease diagnosis. Modified PCR techniques, such as nested PCR and real-time PCR, do have their merits; however, these methods are complicated and require a high-precision thermal cycler that makes them impractical for the diagnosis of SFGR infections in rural areas.

In this study, we developed a sensitive LAMP assay that detects a conserved region of the $о т p B$ gene; the limit of detection of this assay was five copies per reaction or twenty-fold lower than the detection limit for the real-time PCR assay developed in our laboratory (100 copies/reaction) (unpublished data). To evaluate the LAMP assay as a tool for clinical diagnosis, we assayed 11 clinical samples by both LAMP and nested PCR. Of the 11 samples, eight tested positive by the LAMP assay with a limit of detection of five copies per reaction, while none were positive by the nested PCR although the limit of detection was 1 copy $/ \mu \mathrm{L}$. Previous studies have described that the Bst polymerase used in LAMP is less sensitive to inhibitors than Taq polymerase used in the PCR assay [16-18]. Thus, although nested PCR has been reported to be more sensitive for detecting SFGR than the LAMP assay, we show in this study that the LAMP assay is both more accurate and more sensitive than PCR for screening clinical samples. It was notable; however, 


\begin{tabular}{|c|c|c|c|c|}
\hline No. of cases & Diagnosis type & LAMP & Nested PCR & Real-time PCR \\
\hline 1 & gltA gene amplified & Pos. & Neg. & Pos. \\
\hline 2 & gltA gene amplified & Pos. & Neg. & Pos. \\
\hline 3 & 4-fold lgG titer increase & Pos. & Neg. & Neg. \\
\hline 4 & Culture confirmed and gltA gene amplified & Pos. & Neg. & Pos. \\
\hline 5 & 4-fold lgG titer increase & Pos. & Neg. & Neg. \\
\hline 6 & 4-fold IgG titer increase and gltA gene amplified & Pos. & Neg. & Pos. \\
\hline 7 & 4-fold lgG titer increase and gltA gene amplified & Pos. & Neg. & Pos. \\
\hline 8 & Suspected case & Neg. & Neg. & Pos. \\
\hline 9 & Culture confirmed & Neg. & Neg. & Neg. \\
\hline 10 & 4-fold lgG titer increase & Neg. & Neg. & Neg. \\
\hline 11 & 4-fold IgG titer increase and gltA gene amplified & Pos. & Neg. & Pos. \\
\hline
\end{tabular}

${ }^{a}$ All assays were performed in triplicate.

that one seropositive sample was not detected by $о т р B$ LAMP. Because of these observations, we suggest that SFGR infection be confirmed by more than one method to prevent misdiagnosis. Three suspected cases of SFGR were confirmed by LAMP but failed to score as positives by IFA. We suspect that these differences may have resulted from the failure of patients to develop sufficient antibodies for individual differences to be revealed or significant antibody titer during convalescence.

When evaluating the specificity of the $о m p B$ LAMP assay, we tested 27 members of the order Rickettsiales along with several other bacterial pathogens. The results of this study showed that no false-positive amplification was observed with the heterogeneous strains using the SFGR LAMP assay and suggests that LAMP holds promise as an accurate method for differentiating between SFGR and other diseases that cause similar symptoms. The high specificity of LAMP methods has also been reported for other pathogens $[16,17,19-21]$. Compared with conventional PCR techniques that target between two and four genomic regions, LAMP methods can use between four and six primers to target six to eight regions. Consistent with the work presented here, researchers who study other pathogens have also reported the high specificity of the LAMP assay. The reproducibility of $\operatorname{omp} B$ LAMP is relatively high, in that both the $\mathrm{CVi}$ and $\mathrm{CVO}$ are $<5 \%$. Although confirming LAMP results by eye is important in low-technology settings and could reduce amplicon carryover leading to false-positive results, this method was less sensitive than agarose gel electrophoresis in our study (data not shown), as well as in others [18]. This result is in contrast to the findings of Mao et al. [22], which demonstrated that the two methods yielded consistent results. One concern with the SYBR Green method, however, is the risk of contamination that results from opening the tubes to add reagents. We therefore consider it important to take this risk into consideration when debating how to reduce false-positive results during field testing.

In this study, we detected SFGR DNA in samples extracted from whole blood using the LAMP assay, a kit-based assay that is considered more sensitive than freeze-thaw procedures. The problem of using such a kit, however, is that it would increase the assay cost and turn-around time. In support of using freeze-heat procedures, Paris et al. [19] were able to detect Orientia tsutsugamushi (order Rickettsiales) in DNA samples extracted using either a kit or by freeze-thaw procedures, where 7 out of 7 and 5 out of 7 samples were confirmed by these methods, respectively. Although the kit-based method identified SFGR with a $100 \%$ success rate, we feel that the use of boiled samples in the LAMP assay should be reconsidered for greater suitability for use in rural areas.

\section{Conclusions}

A rapid, simple, sensitive, and cost-effective LAMP assay was developed for detecting SFGR in clinical samples. Since the LAMP assay is a fast and sensitive method for testing clinical samples without the aid of sophisticated equipment or complicated operation, this method has the potential to be a powerful tool supporting the diagnosis of SFGR in of China.

\section{Competing interests}

All authors have no competing interests.

\section{Authors' contributions}

LP carried out the primer design of the LAMP and the performance of the LAMP assay for SFGR, participated in the draft the manuscript. LZ

participated in the whole design of the study and performed the statistical analysis and participated in the draft the manuscript. GW collected the cases and sampling and helped to draft the manuscript. QL collected the cases and sampling and helped to draft the manuscript. All authors read and approved the final manuscript. 


\section{Acknowledgments}

We thank Didier Raoult for providing rickettsiae strains for this study. We also thank Robert Massung for providing the Ehrlichia chaffeensis strain and J. S. Dumler for providing the Anaplasma phagocytophilum strain.

This study was funded by the National Basic Research Program of China (973 Program; 2010CB530200 /2010CB530206); the National Natural Science Foundation of China (30771854); and the China-U.S. Collaborative Program on Emerging and Re-emerging Infectious Diseases (1U2GGH000018-01).

\section{Author details}

'Department of Rickettsiology, National Institute for Communicable Disease Control and Prevention, China CDC, Changping P.O.BOX5, Beijing 102206, People's Republic of China. ${ }^{2}$ Department of Infectious Diseases, Peking University First Hospital, Xishenku Street 8, Xicheng District, Beijing 100034, People's Republic of China. 'Laizhou People's Hospital, Wenhua East Road 288, Laizhou, Shandong Province 261400, People's Republic of China.

Received: 5 January 2012 Accepted: 4 October 2012

Published: 11 October 2012

\section{References}

1. Parola P, Paddock CD, Raoult D: Tick-borne rickettsioses around the world: emerging diseases challenging old concepts. Clin Microbiol Rev 2005, 18(4):719-756.

2. Socolovschi C, Mediannikov O, Raoult D, Parola P: Update on tick-borne bacterial diseases in Europe. Parasite 2009, 16(4):259-273.

3. Walker DH, et al: Rickettsiae. In Medical Microbiology. 4th edition. Galveston (TX): University of Texas Medical Branch at Galveston; 1996:Chapter 38

4. Fan MY, Yu XJ, Walker DH: Antigenic analysis of Chinese strains of spotted fever group rickettsiae by protein immunoblotting. AmJTrop Med Hyg 1988, 39(5):497-501.

5. Zhang L, Jin J, Fu X, Raoult D, Fournier PE: Genetic differentiation of Chinese isolates of Rickettsia sibirica by partial ompA gene sequencing and multispacer typing. J Clin Microbiol 2006, 44(7):2465-2467.

6. Fournier PE, Dumler JS, Greub G, Zhang J, Wu Y, Raoult D: Gene sequence-based criteria for identification of new rickettsia isolates and description of Rickettsia heilongjiangensis sp. nov. J Clin Microbiol 2003, 41:5456-5465

7. Chapman AS, Bakken JS, Folk SM, Paddock CD, Bloch KC, Krusell A, Sexton DJ, Buckingham SC, Marshall GS, Storch GA, et al: Rocky Mountain spotted fever, ehrlichioses, and anaplasmosis--United States: a practical guide for physicians and other health-care and public health professionals. MMWR Recomm Rep 2006, 55(RR-4):1-27.

8. Notomi T, Okayama H, Masubuchi H, Yonekawa T, Watanabe K, Amino N, Hase T: Loop-mediated isothermal amplification of DNA. Nucleic Acids Res 2000, 28(12):E63.

9. Luan MC, Yu DZ, Tang L, Zhang LJ: Identification of Orientia tsutsugamushi, spotted fever group and typhus group rickettsia by duplex and nested PCR methods. Asian Pac J Trop Med 2008, 1:1-8.

10. Stenos J, Graves SR, Unsworth NB: A highly sensitive and specific real-time PCR assay for the detection of spotted fever and typhus group Rickettsiae. AmJTrop Med Hyg 2005, 73(6):1083-1085,

11. Brouqui P, Bacellar F, Baranton G, Birtles RJ, Bjoërsdorff A, Blanco JR, Caruso $G$, Cinco $M$, Fournier PE, Francavilla $E$, et al: Guidelines for the diagnosis of tick-born bacterial diseases in Europe. Clin Microbiol Infect 2004, 10(12):1108-1132.

12. Thomas RJ, Dumler JS, Carlyon JA: Current management of human granulocytic anaplasmosis, human monocytic ehrlichiosis and Ehrlichia ewingii ehrlichiosis. Expert Rev Anti Infect Ther 2009, 7(6):709-722.

13. Roux V, Raoult D: Phylogenetic analysis of members of the genus Rickettisae by 16 SrDNA sequnceing. ResMicrobiol 1995, 146:385-396.

14. Pan L, Zhang L, Wang G, Liu Q, Yu Y, Wang S, Yu H, He J: Rapid, simple, and sensitive detection of Anaplasma phagocytophilum by loop-mediated isothermal amplification of the msp2 gene. J Clin Microbiol 2011, 49(12):4117-4120.

15. Mori Y, Kitao M, Tomita N, Notomi T: Real-time turbidimetry of LAMP reaction for quantifying template DNA. J Biochem Biophys Methods 2004, 59(2):145-157.

16. Okada K, Chantaroj S, Taniguchi T, Suzuki Y, Roobthaisong A, Puiprom O, Honda T, Sawanpanyalert P: A rapid, simple, and sensitive loop-mediated isothermal amplification method to detect toxigenic Vibrio cholerae in rectal swab samples. Diagn Microbiol Infect Dis 2010, 66(2):135-139.

17. Thekisoe OM, Kuboki N, Nambota A, Fujisaki K, Sugimoto C, Igarashi I, Yasuda J, Inoue N: Species-specific loop-mediated isothermal amplification (LAMP) for diagnosis of trypanosomosis. Acta Trop 2007, 102(3):182-189.

18. Kaneko H, Kawana T, Fukushima E, Suzutani T: Tolerance of loop-mediated isothermal amplification to a culture medium and biological substances. J Biochem Biophys Methods 2007, 70(3):499-501.

19. Paris DH, Blacksell SD, Newton PN, Day NP: Simple, rapid and sensitive detection of Orientia tsutsugamushi by loop-isothermal DNA amplification. Trans R Soc Trop Med Hyg 2008, 102(12):1239-1246.

20. Nkouawa A, Sako Y, Nakao M, Nakaya K, Ito A: Loop-mediated isothermal amplification method for differentiation and rapid detection of Taenia species. J Clin Microbiol 2009, 47(1):168-174.

21. Curtis KA, Rudolph DL, Owen SM: Rapid detection of HIV-1 by reverse-transcription, loop-mediated isothermal amplification (RT-LAMP). J Virol Methods 2008, 151(2):264-270.

22. Mao XL, Zhou S, Xu D, Gong J, Cui HC, Qin QW: Rapid and sensitive detection of 342 Singapore grouper iridovirus by loop-mediated isothermal amplification. J Appl Microbiol 2008, 105(2):389-397.

\section{doi:10.1186/1471-2334-12-254}

Cite this article as: Pan et al: Rapid, simple, and sensitive detection of the ompB gene of spotted fever group rickettsiae by loop-mediated isothermal amplification. BMC Infectious Diseases 2012 12:254.

\section{Submit your next manuscript to BioMed Central and take full advantage of:}

- Convenient online submission

- Thorough peer review

- No space constraints or color figure charges

- Immediate publication on acceptance

- Inclusion in PubMed, CAS, Scopus and Google Scholar

- Research which is freely available for redistribution 